\title{
Results of selective early operation in myelomeningocele
}

\author{
GORDON D. STARK and MARGARET DRUMMOND \\ From the Royal Hospital for Sick Children and Department of Child Life and Health, University of Edinburgh
}

Stark, G. D., and Drummond, M. (1973). Archives of Disease in Childhood, 48, 676. Results of selective early operation in myelomeningocele. In a 6 -year period 163 unselected newborn infants with open myelomeningocele were assessed. $48 \%$, considered to have the most favourable prognosis, were selected for early back closure and vigorous subsequent treatment. The more severely affected remainder were given only symptomatic treatment unless long-term survival seemed likely. The major adverse criteria were severe paralysis, gross head enlargement, and spinal deformity such as kyphosis. More than $70 \%$ of selected infants were alive at 6 years, whereas more than $80 \%$ of untreated infants were dead at 3 months.

The follow-up results are compared with those of routine early operation (Lorber, 1971a). After 1 year, the overall survival levelled out at $40 \%$ (cf $60 \%$ ). The survivors were, however, less severely handicapped. Only $25 \%$ were mainly or entirely in wheelchairs (cf $49 \%$ ). Only $16 \%$ had upper urinary tract damage in addition to incontinence (cf $34 \%$ ). A combination of mental and severe physical handicap occurred in only $20 \%$ (cf $36 \%$ ). Severe disability was encountered mainly in children who had suffered from complications, e.g. ventriculitis, unforeseeable at birth.

It is concluded that the overall results of selective early operation compare favourably with those of purely conservative management on the one hand, and with routine early operation on the other. It is suggested that this policy offers the best prospects of independence for the less severely affected child, and the least distress and suffering for the grossly afflicted.

Routine early closure of myelomeningocele was advocated in Sheffield a decade ago (Sharrard et al., 1963) and has since become standard practice in many centres in Great Britain and abroad. The only detailed report of the results of unselective early operation is that of Lorber (1971a). The end results of an unparalleled expenditure of resources on myelomeningocele were so disappointing that he went on to advocate a policy of selection based on certain major adverse criteria at birth, which would have excluded just over half from operation. As yet, however, there are no published reports on the actual effectiveness of such a policy.

Since the selection criteria employed at the Royal Hospital for Sick Children, Edinburgh, where routine early operation has never been accepted, accord closely with those now defined by Lorber, it is of interest to compare our results with those of the nonselective policy employed in Sheffield.

Received 12 February 1973.

\section{Patients and methods of study}

Between April 1965 and March 1971, 163 unselected infants with open myelomeningoceles were admitted to the spina bifida unit. More than $98 \%$ were under 24 hours of age on admission, the range being 1 to 64 hours. On admission every child was subjected to a detailed paediatric and neurological examination by one of us, as previously described (Stark, 1971), and detailed records kept as part of a prospective study. No predefined criteria for selection were employed, but each case was considered on its merits-social as well as medical and surgical factors being taken into consideration.

Patients fell into two groups. In group A 78 infants $(48 \%)$ were subjected to early operation, associated problems were dealt with systematically, and complications treated vigorously. The 85 patients $(52 \%)$ in group B were not subjected to operation. They were retained in the unit where they received good nursing care, were fed normally, and kept comfortable. In the event of life-threatening situations, such as ventriculitis, antibiotics were withheld and therapy confined to analgesics, such as heroin. In infants in this group 
whose lesions epithelialized and who seemed likely to survive indefinitely, there was no hesitation in controlling the hydrocephalus.

The period of follow-up ranged from 1 to 6 years during which time survivors of both groups were subjected to regular paediatric, urological, orthopaedic, and neurological assessments in the spina bifida unit. In children reaching the age of 4 , psychometric assessment was carried out; in younger children a clinical developmental assessment was made.

The grading of specific disabilities and overall handicap used in the study is a refinement of that used by Lorber (1971a) to facilitate comparison. As will be seen from Tables I and II, the category of overall

TABLE I

Grading of handicap at follow-up

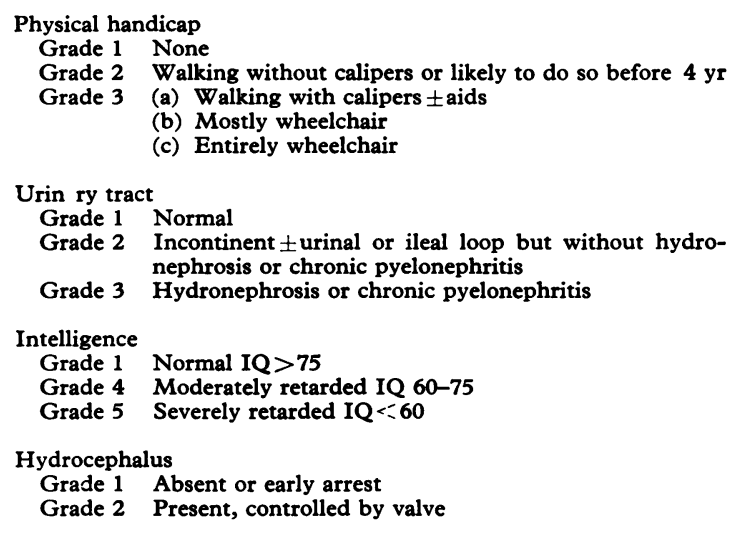

\section{TABLE II}

Overall disability at follow-up (derived from Lorber, 1971a)

Category 1 No handicap, i.e. no grade $>1$

Category 2 Moderate handicap, i.e. no grade $>2$

Category 3 Severe physical handicap with normal intellectual development, i.e. no grade $>3$

Category 4 Severe physical handicap with moderate mental

retardation, i.e. IQ grade $4^{\star}$
Category 5 Severe physical handicap with severe mental retardation, i.e. IQ grade $5^{\star}$

*No moderately or severely mentally retarded child had less than grade 3 physical handicap.

disability is computed from the grading of particular handicaps. Mental retardation is heavily weighted so that all children so affected appear in categories 4 and 5 . The categories of overall handicap are directly comparable with those defined by Lorber (1971a).

\section{Results}

Comparability of selective criteria. Lorber (1971a) considered that operation should be withheld in infants with severe paraplegia*, gross head enlargement, kyphosis, major associated defects, or severe birth injury. The distribution of these factors in groups $\mathbf{A}$ and $\mathbf{B}$ are compared in Fig. 1. One or more major adverse factors were

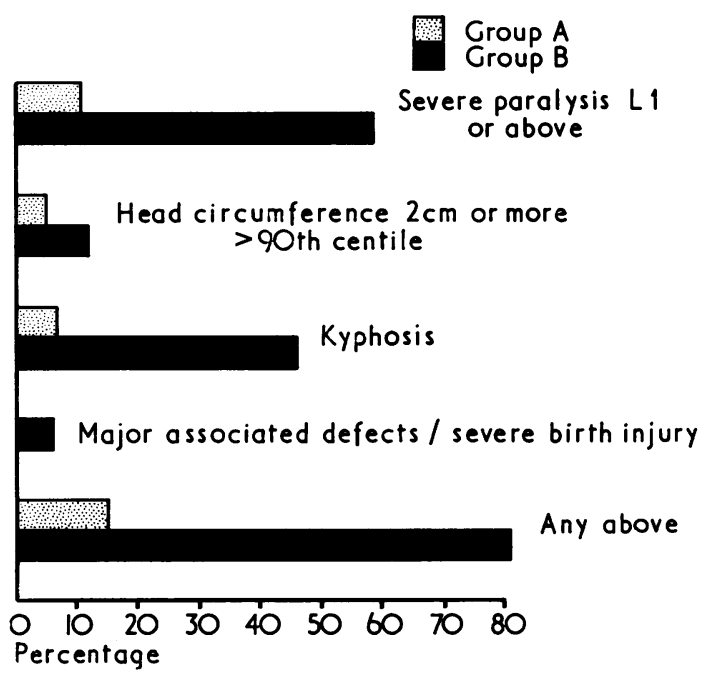

FIG. 1.-Distribution of major adverse criteria on admission in infants selected for early back closure (group $A$ ) and nonsurgical management (group $B$ ).

present in only $15 \%$ of group A but in $81 \%$ of group B, suggesting that the criteria employed in Edinburgh, over the last 7 years, were similar to those now advocated in Sheffield. Furthermore, our selective policy resulted in operation on almost exactly the same proportion of patients as would the criteria of Lorber (1971a).

In retrospect there was a variety of reasons for not operating on the 16 patients without any of the major adverse criteria at the initial examination. Some infants had adverse criteria just short of those defined, some deteriorated significantly (in lower limb function) immediately after the initial assessment, and in other cases parents refused consent for operation.

Similarly, there were a number of explanations for operating on the 12 infants who showed major adverse criteria. In some, with hindsight, there

*Lorber is somewhat ambiguous in defining the degree of paralysis (his Grades 4 and 5) which constitutes a major adverse criterion. It approximates, however, to a voluntary motor level of $\mathrm{Ll}$ or above, which we have assumed for the purposes of comparison. 
TABLE⿳亠丷厂

Life-table of 163 infants admitted with open myelomeningocele $\stackrel{\vec{F}}{\vec{*}}$

\begin{tabular}{|c|c|c|c|c|c|c|}
\hline & & & & & & $\begin{array}{c}\text { Maximum } \\
\text { possible no. } \\
\text { surviving }\end{array}$ \\
\hline & & & & & Group A & 78 \\
\hline & & & & & Group B & 85 \\
\hline & & & & & Total & 163 \\
\hline & \multicolumn{3}{|c|}{$2 \mathrm{yr}$} & \multicolumn{3}{|c|}{$3 \mathrm{yr}$} \\
\hline & $\begin{array}{c}\text { Maximum } \\
\text { possible } \\
\text { surviving }\end{array}$ & $\begin{array}{c}\text { Actual } \\
\text { no. } \\
\text { alive }\end{array}$ & $\%$ & $\begin{array}{l}\text { Maximum } \\
\text { possible } \\
\text { surviving }\end{array}$ & $\begin{array}{l}\text { Actual } \\
\text { no. } \\
\text { alive }\end{array}$ & $\%$ \\
\hline $\begin{array}{l}\text { Group A } \\
\text { Group B }\end{array}$ & $\begin{array}{l}68 \\
63\end{array}$ & $\begin{array}{r}54 \\
6\end{array}$ & $\begin{array}{l}79 \\
10\end{array}$ & $\begin{array}{l}56 \\
49\end{array}$ & $\begin{array}{r}42 \\
3\end{array}$ & $\begin{array}{r}75 \\
6\end{array}$ \\
\hline Total & 131 & 60 & 46 & 105 & 45 & 43 \\
\hline
\end{tabular}

was an error of judgement, some had asymmetrical lesions with a severe paralysis in only one leg, and in others parents insisted on operation.

Survival. The percentage of survivors in groups A and B and in the whole series is shown in Fig. 2 and Table III. $18 \%$ of surgically treated infants died in the first 3 months of life, but mortality was thereafter low and more than $70 \%$ were alive at

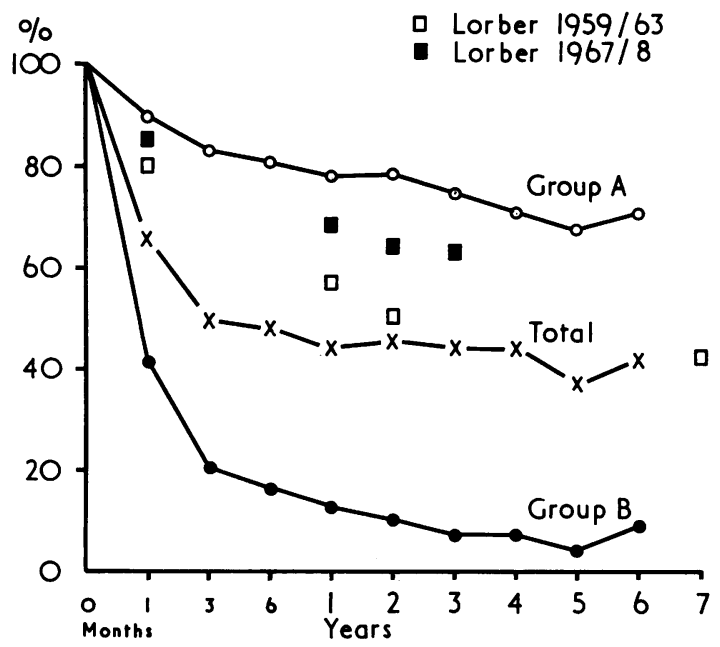

Fig. 2.-Survival (life-table basis) in infants subjected to early back closure (group $A$ ), no back closure (group B), and in total series (groups $A$ and $B$ ), compared with survival in infants subjected to routine early operation (Lorber, 1971a).
6 years. By contrast, over $80 \%$ of untreated patients were dead by 3 months. From 1 year onwards, the overall survival rate levelled off at just over $40 \%$. In Sheffield the overall survival in the 1959/63 series (Lorber, 1971a) was very similar to ours after the first year of life. For patients born in $1967 / 68$ it was, however, $20 \%$ greater.

\section{Quality of survival.}

(a) Physical handicap. The severity of physical handicap, as graded in Table I, is considered in Fig. 3 in which the following groups are compared:

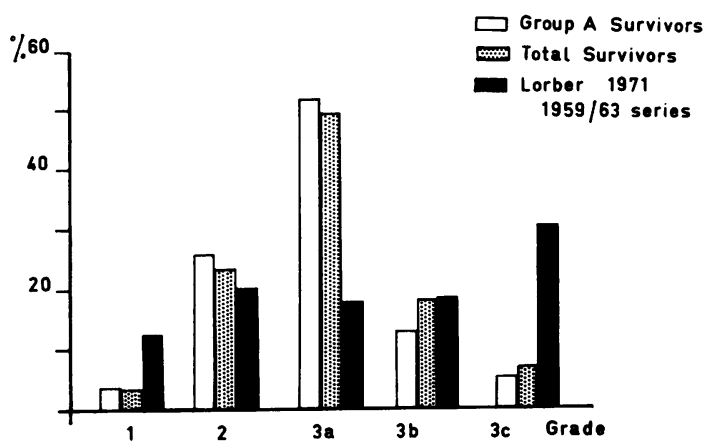

Fig. 3.-Physical handicap at latest follow-up in surviving infants selected for early operation (group $A$ ), and in total survivors (groups $A$ and $B$ ), compared with that in survivors of routine early operation (Lorber, 1971a). Handicap increases from Grade 1 (normal) to Grade 3c (entirely wheelchair life). 
Group $A$ had early back closure, group $B$ had no back closure

\begin{tabular}{|c|c|c|c|}
\hline \multicolumn{4}{|c|}{ Actual no. and percentage alive } \\
\hline $1 \mathrm{mth}$ & $3 \mathrm{mth}$ & $6 \mathrm{mth}$ & $1 \mathrm{yr}$ \\
\hline $\begin{array}{c}70 \\
90 \% \\
35 \\
41 \%\end{array}$ & $\begin{array}{c}64 \\
82 \% \\
16 \\
19 \%\end{array}$ & $\begin{array}{c}62 \\
80 \% \\
14 \\
15 \%\end{array}$ & $\begin{array}{c}60 \\
77 \% \\
10 \\
12 \%\end{array}$ \\
\hline $\begin{array}{l}105 \\
64 \%\end{array}$ & $\begin{array}{c}80 \\
49 \%\end{array}$ & $\begin{array}{c}76 \\
47 \%\end{array}$ & $\begin{array}{c}70 \\
43 \%\end{array}$ \\
\hline
\end{tabular}

\begin{tabular}{|c|c|c|c|c|c|c|c|c|}
\hline \multicolumn{3}{|c|}{$4 \mathrm{yr}$} & \multicolumn{3}{|c|}{$5 \mathrm{yr}$} & \multicolumn{3}{|c|}{$6 \mathrm{yr}$} \\
\hline $\begin{array}{l}\text { Maximum } \\
\text { possible } \\
\text { surviving }\end{array}$ & $\begin{array}{c}\text { Actual } \\
\text { no. } \\
\text { alive }\end{array}$ & $\%$ & $\begin{array}{c}\text { Maximum } \\
\text { possible } \\
\text { surviving }\end{array}$ & $\begin{array}{c}\text { Actual } \\
\text { no. } \\
\text { alive }\end{array}$ & $\%$ & $\begin{array}{c}\text { Maximum } \\
\text { possible } \\
\text { surviving }\end{array}$ & $\begin{array}{c}\text { Actual } \\
\text { no. } \\
\text { alive }\end{array}$ & $\%$ \\
\hline $\begin{array}{l}46 \\
35\end{array}$ & $\begin{array}{r}33 \\
2\end{array}$ & $\begin{array}{r}72 \\
6\end{array}$ & $\begin{array}{l}30 \\
26\end{array}$ & $\begin{array}{r}20 \\
1\end{array}$ & $\begin{array}{r}67 \\
4\end{array}$ & $\begin{array}{l}14 \\
12\end{array}$ & $\begin{array}{r}10 \\
1\end{array}$ & $\begin{array}{r}71 \\
8\end{array}$ \\
\hline 81 & 35 & 43 & 56 & 21 & 38 & 26 & 11 & 42 \\
\hline
\end{tabular}

group A (operated) survivors, total survivors (operated and unoperated), and Sheffield survivors of routine early operation (Lorber, 1971a). There is a shift to the right of Sheffield patients of whom $49 \%$ are mainly or entirely dependent on wheelchairs (Grades $3 b$ and $3 c$ ) compared with $25 \%$ of total Edinburgh survivors and $19 \%$ of group A survivors.

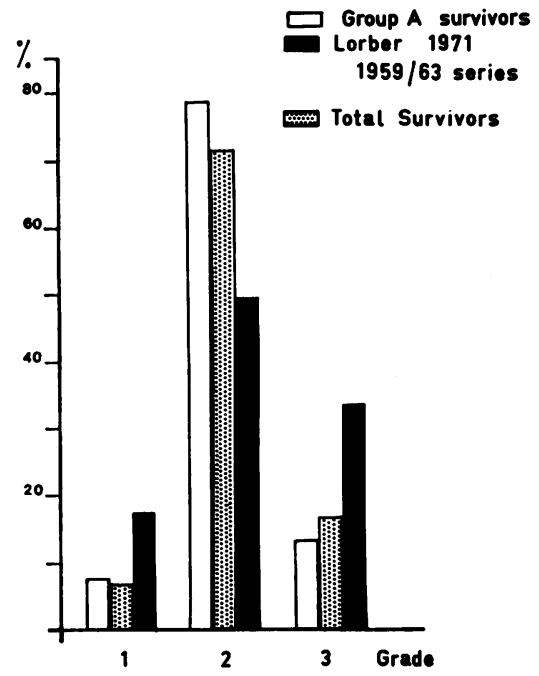

FIG. 4.-Condition of urinary tract at latest follow-up in surviving infants selected for early operation (group $A$ ) and in total survivors (groups $A$ and $B$ ) compared with that in survivors of routine early operation (Lorber, 1971a). Grade 1 normal, Grade 2 incontinent, Grade 3 incontinent with upper urinary tract damage. (b) Urinary tract problems. These are similarly compared in Fig. 4 which also shows a greater proportion of Sheffield survivors in the worst grade. $34 \%$ of them had not only incontinence but upper urinary tract damage (Grade 3), compared with $16 \%$ in total Edinburgh survivors and $13 \%$ in group A survivors. The higher proportion of Sheffield children classified as having a normal urinary tract probably, like a similar phenomenon in physical handicap (Fig. 3), reflects subjective differences in grading. In Edinburgh 'normal' was taken to mean normal: if young children had been included who had reflex bladders with sensation and who might later become continent, the proportion of 'normals' would have been trebled.

(c) Intelligence and hydrocephalus (Fig. 5a and b). Moderate or severe mental handicap occurred in $33 \%$ of Sheffield survivors and in $20 \%$ of Edinburgh survivors (15\% of group A survivors). By contrast, $85 \%$ of Edinburgh children and only $56 \%$ of Sheffield survivors had CSF shunts. This difference is probably due to the policy in Sheffield of avoiding operation wherever possible in view of the hazards of the ventriculoatrial shunt (Lorber, 1971b; Stark, 1972). In Edinburgh, however, where the safer ventriculoperitoneal shunt has been used, recourse to operation has been earlier.

(d) Overall disability. The categories of overall disability defined by Lorber (1971a) have been detailed in Table II. Their distribution in survivors is shown in Fig. 6. No Edinburgh survivors could be classified as entirely normal (cf 


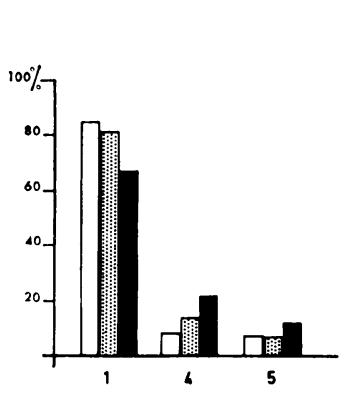

(a)

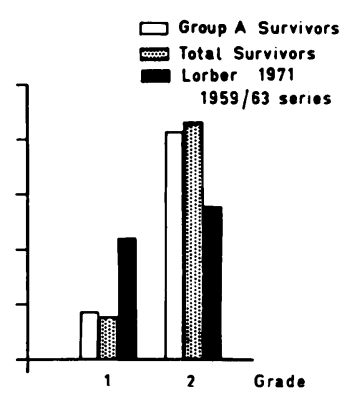

(b)
FIG. 5.-(a) Intelligence at latest follow-up in surviving infants selected for early operation (group $A$ ) and in total survivors (groups $A$ and $B$ ) compared with that of survivors of routine early operation (Lorber, 1971a). Mental handicap increases from Grade 1 (normal) to Grade 5 $(I Q<60)$. (b) Status of hydrocephalus at latest follow-up in surviving infants selected for early operation (group $A$ ) and in total survivors (groups $A$ and $B$ ), compared with that in survivors of routine early operation (Lorber, 1971a). Grade 1 hydrocephalus absent or arrested early, Grade 2 hydrocephalus controlled by shunt.

$2 \%$ in Sheffield). At the other extreme, however, $36 \%$ of Sheffield survivors were not only severely physically handicapped but also moderately or severely mentally handicapped (categories 4 and 5). The comparable figures for Edinburgh are $20 \%$ (total survivors) and $15 \%$ (group A survivors).

\section{Discussion}

Information is now available on the results of three possible approaches to the problem of open myelomeningocele.

(1) Conservative management (i.e. no operation at all). Laurence and Tew (1971) described the natural history of 381 cases of myelomeningocele born in South Wales in 1956-62. When followed up in 1968 , only $10 \%$ were still alive and $70 \%$ of the survivors were considered to be severely or very severely handicapped, or to be in a 'vegetative' state. Ignoring stillbirths and first-day deaths, it was estimated that only 1 in 7 untreated infants would reach school age and only 1 in 70 would be fit to attend a normal school (Lancet, 1969). While a policy of nonintervention results in early death of the most severely afflicted, without the benefits of modern treatment disability of the less severely affected survivors is undoubtedly increased.

(2) Unselective early operation. With the publication of the results of a 'controlled' trial of early and delayed back closure in Sheffield (Sharrard

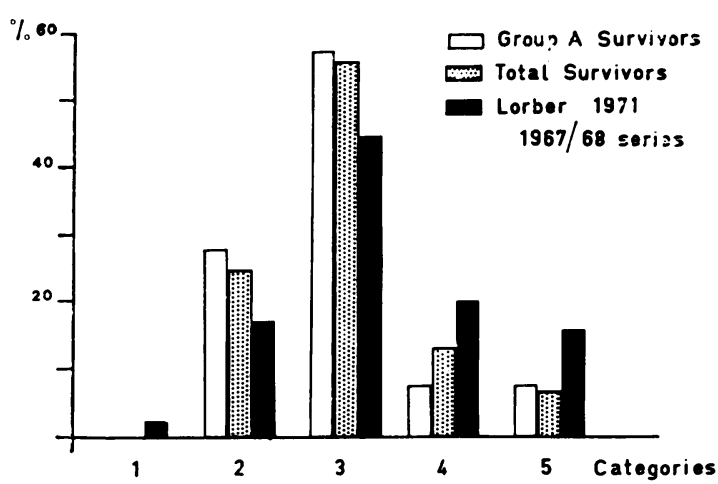

FIG. 6.-Overall disability in surviving infants selected for early operation (group $A$ ) and in total survivors (groups $A$ and $B)$, compared with that in survivors of routine early operation (Lorber, 1971a). Disability increases from Category 1 (normal) to Category 5 (severe physical and mental handicap).

et al., 1963), the pendulum swung in many major centres to a policy of routine early operation in every case. Favourable results were reported by the Liverpool workers, but their series, which included cranium bifidum, was selected in so far as 57 out of 157 liveborn infants were either not referred for or not subjected to operation (Rickham and Mawdsley, 1966; Mawdsley, Rickham, and Roberts, 1967). Since none with myelomeningocele survived 6 months, this unoperated group must have included the most severely affected. Similar selection occurred in a later report in which no fewer than $42 \%$ of survivors of open myelomeningocele were considered at follow-up to be 'normal or near normal' (Mawdsley and Rickham, 1969). The only series so far reported in which there was no evidence of significant selection before hospital admission and in which all infants were subjected to early operation is that of Lorber (1971a). The results are extremely disappointing. In Lorber's words, 'Massive efforts in treatment have led to a considerably increased survival rate, but the large majority of survivors have major physical defects and are often mentally retarded'. In addition to the handicaps documented by Lorber (1971a), recent papers have emphasized the immense impact of the condition on family and social life (Freeston, 1971; Walker, Thomas, and Russell, 1971).

The financial cost of this policy is enormous (Lightowler, 1971), and even to achieve results comparable to those in Sheffield a very elaborate and ever-expanding service would be necessary (Ministry of Health, 1968). Such a service is, at present, available in few areas in this country. The 
morality is doubtful, therefore, of recommending early operation on infants for whom a full range of medical, surgical, educational, and social support cannot be promised.

(3) Selective early operation. From time to time voices crying in the wilderness have advocated selective surgery in myelomeningocele (Ingram, 1965; Matson, 1968; Forrester, 1968; Stark, 1971). Precise selection criteria have, however, seldom been specified and this is the first report of results of selective early operation.

Effectiveness of selective policy. The effectiveness of this policy has been compared as closely as possible with that of unselective early operation documented by Lorber (1971a). Despite selection of only $50 \%$ for operation, by the age of 2 years the overall survival in the Edinburgh series was only $20 \%$ less than the best survival figures (1967-68) from Sheffield. It is clear that even with routine early operation and intensive treatment, natural selection continues to weed out the more severely affected. The incidence of severe physical disability, upper urinary tract damage, and severe mental handicap are each about $20 \%$ lower in Edinburgh. It is suggested that these more favourable results are due to the policy of selective early operation rather than superior management in Edinburgh.

The results, however, fall short of those predicted by Lorber (1971a) for selective early surgery using essentially the same criteria. Apart from possible inferior management in Edinburgh, there appear to be two reasons for Lorber's over-optimism. Firstly, he does not allow for survival of some infants with major adverse criteria who are not subjected to operation. Though the numbers are small (only 6 infants in group B survived the age of 2 years), survival of these infants who are, by definition, severely affected, does impair the overall results. This can be seen by comparison of disabilities in total and group A survivors in Fig. 3 to 6. Secondly, promising infants subjected to early operation are still liable to damaging secondary complications. Among group A survivors, 12 children $(22 \%)$ have mental and/or very severe physical handicap (mainly wheelchair existence). 3, who have both handicaps, had major adverse criteria at birth and were, in retrospect, wrongly selected. However, all 10 with very severe physical handicap and 6 out of 8 with mental handicap had suffered severe secondary complications unforeseeable at birth, which greatly increased their disability.
Objections to selective policy. It has been stated that a selective policy is impracticable since 'it is virtually impossible to assess the potential of the newborn infant with a myelomeningocele' (Eckstein, 1968). Since, however, it has been established that the policy is not only practicable but effective, there are few remaining grounds for objection. One valid criticism which has caused some anxiety is that the severely affected infant whose back has not been repaired may, nonetheless, survive with greater disability than he would have had with early operation. Since they have had little lower limb function to lose, and since it has been our practice to control hydrocephalus in such infants who are bent on survival, it is doubtful whether the handicaps of any have been increased. There is no doubt, however, that parental acceptance of these infants who, having been mourned, return like Lazarus from the grave, is prejudiced. Nevertheless, only one has not been discharged home.

It has been eloquently and sincerely argued that life must be saved at all costs and that, however grossly malformed the infant, the doctor has no right to withhold treatment (Zachary, 1968; Nash, 1970). It might equally well be argued that, since without surgical treatment the vast majority of these infants will die in the first year of life, the doctor should be required to justify intervention rather than nonintervention. It must be remembered that when they 'consent' to operation many mothers have not recovered from the stress of labour and the effects of analgesic drugs; that few parents at this stage have any real understanding of the problems involved; and that the ethical and religious views of the doctor may not be shared by the parents who will have to look after the child. In a society which acquiesces-rightly or wrongly-in the destruction of fetal life because of a mere possibility of handicap or because a normal child might inconvenience the parents, it is increasingly difficult to justify extreme measures to save the life of an infant who is manifestly grossly handicapped (Oppé, 1972).

Scope for improvement. It seems clear that any one of the major adverse criteria, as defined by Lorber, is predictive of severe disability. Application of these criteria, however, reduces but does not abolish the occurrence of severe handicap. While this must partly be accepted as inevitable due to unforeseen later complications, it must be asked whether precision of the selection criteria could not be increased. For example, in addition to the major criteria, the following factors might be considered in planning selection.

(1) Other spinal anomalies, e.g. the short com- 
pressed spine with multiple congenital anomalies; structural scoliosis. These factors can be no less disabling than kyphosis.

(2) Less severe paralysis. As stated earlier, Lorber's 'severe paralysis' has been interpreted as meaning absence of voluntary function in muscles innervated below $\mathrm{Ll}$. Lower limb function, however, may scarcely be better in other cases. For example (a) the infant in whom some voluntary movement below $\mathrm{Ll}$ is present but very weak (MRC score <3), (b) the infant with a partial cord transection in whom voluntary movement is present below $\mathrm{Ll}$ but much weaker than reflex activity, and who is likely later to have a severe spastic paraplegia, and (c) the infant with strong voluntary hip flexion and adduction only (i.e. motor level L $2 / 3$ ) who is likely to have little residual voluntary movement after correction of the inevitable hip deformity.

(3) Social factors. In certain circumstances factors other than those already described may be relevant in selection. For example, stricter selection criteria are likely to be more appropriate in developing countries whose medical, social, and educational resources are more limited. Adverse factors in the family such as illegitimacy may also have a profound influence on the outcome for the child.

If, as seems likely, selective early operation is introduced in other centres, it is to be hoped that the neonatal findings will be carefully documented so that selection criteria can be compared in different series and further refined.

If selection criteria are more strict and operation withheld in much more than $50 \%$, increased survival of the unoperated is likely to vitiate results. These could, however, at any time be improved by more positive steps to discourage survival such as subcaloric feeding (Colliss, 1972) or even frank euthanasia. This would, however, present more serious ethical problems than the policy we have described.

An intermediate policy has recently been suggested of early back closure not only in favourable cases, but also in some of the more severely affected with the object of providing more time for assessment before a second decision is taken to proceed (or not) with further treatment (Laurence and Tew, 1971; Colliss, 1972). This policy has little to recommend it. It is based on the unjustified assumption that accurate assessment is not possible within the first 24 hours of life. The prolonged period of uncertainty might be intolerable for parents and, with closure of the lesion, the child who proved to be severely affected would be more likely to survive.

There is enormous scope for prevention and more effective therapy of damaging complications such as ventriculitis, intracranial haemorrhage, valve complications, etc. With increased concentration of resources on treatment and habilitation of the less severely affected patients, such improvement can be expected.

This work was supported financially by Action for the Crippled Child and spiritually by Dr. T. T. S. Ingram and Professor J. O. Forfar. We are grateful to our surgical colleagues, Mr. F. H. Robarts, Miss R. M. Mackay, Mr. W. H. Bisset, Mr. J. F. Shaw, and Professor D. H. Hamblen; to our nursing colleagues Miss J. Mander and Miss M. Watson; to Mrs. Sheena Maxwell for psychometric assessments; and to Miss U. Burnet and Miss C. Brydone for assistance.

\section{REFERENCES}

Colliss, V. R. (1972). The effects of selective treatment of myelomeningocele on a neonatal unit. In Studies in Hydrocephalus and Spina Bifida. Developmental Medicine and Child Neurology, 14, Suppl. 27, 34.

Eckstein, H. B. (1968). Myelomeningocele, basic considerations. Hospital Medicine, 2, 896.

Forrester, R. M. (1968). Ethical and social aspects of treatment of spina bifida. Lancet, 2, 1033.

Freeston, B. M. (1971). An enquiry into the effect of a spina bifida child upon family life. Developmental Medicine and Child Neurology, 13, 456.

Ingram, T. T. S. (1965). Immediate repair of spina bifida. Action for the crippled child monograph. Proceedings of a Symposium on Spina Bifida, 4 b. National Fund for Research into Poliomyelitis and other Crippling Diseases, London.

Lancet (1969). Editorial. Natural history of spina bifida, 2, 34.

Laurence, K. M., and Tew, B. J. (1971). Natural history of spina bifida cystica and cranium bifidum cysticum. Archives of Disease in Childhood, 46, 127.

Lightowler, C. D. R. (1971). Meningomyelocele: the price of treatment. British Medical fournal, 2, 385.

Lorber, J. (1971a). Results of treatment of myelomeningocele. An analysis of 524 unselected cases with special reference to possible selection for treatment. Developmental Medicine and Child Neurology, 13, 279.

Lorber, J. (1971b). Medical and surgical aspects in the treatment of congenital hydrocephalus. Neuropädiatrie, 2, 239.

Matson, D. D. (1968). Surgical treatment of myelomeningocele. Pediatrics, 42, 225.

Mawdsley, T., and Rickham, P. P. (1969). Further follow-up study of early operation for open myelomeningocele. Developmental Medicine and Child Neurology, Suppl. 20, 8.

Mawdsley, T., Rickham, P. P., and Roberts, J. R. (1967). Longterm results of early operation of open myelomeningoceles and encephaloceles. British Medical fournal, 1, 663.

Ministry of Health (1968). Surgery for the Newborn. Report of the Foint Sub-Committee of the Standing Medical Advisory Committees. H.M.S.O., London.

Nash, D. F. E. (1970). The impact of total care with special reference to myelodysplasia. Developmental Medicine and Child Neurology, Suppl. 22, 1.

Oppé, T. E. (1972). Operating on spina bifida. World Medicine, 7, (Annual Review), 47.

Rickham, P. P., and Mawdsley, T. (1966). The effect of early operation on the survival of spina bifida cystica. Developmental Medicine and Child Neurology, Suppl. 11, 20.

Sharrard, W. J. W. Zachary, R. B., Lorber, J., and Bruce, A. M. (1963). A controlled trial of immediate and delayed closure of spina bifida cystica. Archives of Disease in Childhood, 38, 18. 
Stark, G. D. (1971). Neonatal assessment of the child with a myelomeningocele. Archives of Disease in Childhood, 46, 539.

Stark, G. D. (1972). Conservative treatment of hydrocephalus. Developmental Medicine and Child Neurology, 14, 804.

Walker, J. H., Thomas, M., and Russell, I. T. (1971). Spina bifida - and the parents. Developmental Medicine and Child Neurology, 13, 462.
Zachary, R. B. (1968). Ethical and social aspects of treatment of spina bifida. Lancet, 2, 274.

Correspondence to Dr. G. D. Stark, Department of Child Life and Health, University of Edinburgh, 25 Hatton Place, Edinburgh EH9 1UB. 